\title{
Genetic parameters for energy balance, feed efficiency, and related traits in Holstein cattle
}

\author{
D. M. Spurlock, ${ }^{\star 1}$ J. C. M. Dekkers, ${ }^{*}$ R. Fernando, ${ }^{\star}$ D. A. Koltes, ${ }^{\star}$ and A. Wolc ${ }^{\star} \dagger$ \\ *Department of Animal Science, lowa State University, Ames 50011 \\ †Department of Genetics and Animal Breeding, Poznan University of Life Sciences, Poland
}

\begin{abstract}
Objectives of the current study were to estimate genetic parameters in Holstein cows for energy balance (EB) and related traits including dry matter intake (DMI), body weight (BW), body condition score (BCS), energy-corrected milk (ECM) production, and gross feed efficiency (GFE), defined as the ratio of total ECM yield to total DMI over the first $150 \mathrm{~d}$ of lactation. Data were recorded for the first half of lactation on 227 and 175 cows in their first or later lactation, respectively. Random regression models were fitted to longitudinal data. Also, each trait was averaged over monthly intervals and analyzed by single and multivariate animal models. Heritability estimates ranged from 0.27 to $0.63,0.12$ to $0.62,0.12$ to $0.49,0.63$ to 0.72 , and 0.49 to 0.53 for DMI, ECM yield, EB, BW, and BCS, respectively, averaged over monthly intervals. Daily heritability estimates ranged from 0.18 to $0.30,0.10$ to $0.26,0.07$ to $0.22,0.43$ to 0.67 , and 0.25 to 0.38 for DMI, ECM yield, EB, BW, and BCS, respectively. Estimated heritability for GFE was 0.32. The genetic correlation of EB at $10 \mathrm{~d}$ in milk (DIM) with EB at 150 DIM was -0.19 , suggesting the genetic regulation of this trait differs by stage of lactation. Positive genetic correlations were found among DMI, ECM yield, and BW averaged over monthly intervals, whereas correlations of these traits with BCS depended upon stage of lactation. Total ECM yield for the lactation was positively correlated with DMI, but a negative genetic correlation between total ECM yield and EB was found. However, the genetic correlation between total ECM yield and $\mathrm{EB}$ in the first month of lactation was -0.02 , indicating that total production is not genetically correlated with EB during the first month of lactation, when negative EB is most closely associated with diminished fitness. The genetic correlation between GFE and EB ranged from -0.73 to -0.99 , indicating that selection for more efficient cows would favor a lower energy status. How-
\end{abstract}

Received February 2, 2012.

Accepted May 27, 2012.

${ }^{1}$ Corresponding author: moodyd@iastate.edu ever, the genetic correlation between EB in the first month of lactation and GFE calculated from 75 to 150 DIM was not significant, indicating that the unfavorable correlation between GFE and EB in early lactation may be minimized with alternative definitions of efficiency. Thus, EB, GFE and related traits will likely respond to genetic selection in Holstein cows. However, the impact of selection for improved feed efficiency on EB must be carefully considered to avoid potential negative consequences of further reductions in $\mathrm{EB}$ at the onset of lactation.

Key words: heritability, feed efficiency, dairy cattle

\section{INTRODUCTION}

Long-term selection for increased production, combined with improved management practices have dramatically increased average milk yield in dairy cows over past decades. For example, average milk production per cow in the United States increased from 8,271 to $9,613 \mathrm{~kg} / \mathrm{yr}$ from 2000 to 2010 (USDA-NASS, 2012). However, as milk production increases, producers must also be cognizant of potential correlated changes that may affect fitness traits and welfare of dairy cows (Oltenacu and Broom, 2010). Energy balance (EB) is the difference between energy intake and energy expenditure for lactation, growth, reproduction, and maintenance. When energy expenditures exceed intake, cows experience negative EB and mobilize energy reserves from body tissue to correct the energy deficit. Because all biological processes rely upon a common energy reservoir, negative EB is unfavorably associated with reproductive performance, metabolic imbalance, and other health conditions in high-producing dairy cows (Pryce et al., 2001; Veerkamp et al., 2001; Oltenacu and Broom, 2010). Thus, EB has been investigated as a potential selection target to aid in improvement of fitness traits in the context of increasing production.

The dairy industry is also facing increased pressure to improve production efficiency, primarily due to the need to maintain profitability in an era of increasing feed costs, and a desire to improve environmental stewardship (Connor et al., 2012). The most basic definition 
of production efficiency is gross feed efficiency (GFE), or the ratio of milk yield or milk energy to DMI or energy intake (Brody, 1945). Although ratio traits have limitations for use in selection (Simm et al., 1987), it is important to understand the genetic relationships among GFE, EB, and production traits as strategies to improve production efficiency are considered.

Several recent studies have described the genetic regulation of $\mathrm{EB}$, with heritability estimates ranging from 0.03 to 0.35 (Hüttmann et al., 2009; Verbyla et al., 2010; Buttchereit et al., 2011). Likewise, GFE has been described as a moderately heritable trait, with heritability estimates ranging from 0.14 to 0.37 (van Arendonk et al., 1991; Vallimont et al., 2011). An unfavorable genetic correlation between GFE and BCS $(-0.70)$ has been reported based on field data (Vallimont et al., 2011), but estimates of the genetic correlation between GFE and EB are lacking.

Objectives of the current study were to estimate genetic parameters for EB, GFE, DMI, BW, BCS, and production traits. Random regression and multitrait methodologies were used, and differences between first and later parities, as well as differences among the first 5 mo of lactation are described. Particular emphasis was placed on description of genetic correlations among GFE and other traits at different stages of lactation.

\section{MATERIALS AND METHODS}

\section{Animals and Data Collection}

All animal experiments were approved by the Institutional Animal Care and Use Committee of Iowa State University (Ames). Data were collected from 402 Holstein cows at the Iowa State University Dairy between March 8, 2008, and November 5, 2010. Data were collected from a single lactation per cow, with $227,83,50,31,8,2$, and 1 cows in their first through seventh lactation, respectively. The cows descended from 93 sires and 321 dams, and 83 dam-daughter pairs were included in the data set. A 5-generation pedigree was used, and included 2,414 individuals. Data were collected from approximately 2 through 150 DIM. This period was chosen to characterize EB throughout the duration of negative EB, while optimizing use of facilities.

Cows were milked twice daily, and milk yield was recorded at each milking. Milk composition was determined from a single milk sample collected weekly during a morning milking. Fat, protein, and lactose percentages were determined from these weekly samples by Dairy Lab Services Inc. (Dubuque, IA). Monthly milk fat and protein composition determined through the DHIA program according to its uniform data col- lection procedures (http://www.DHIA.org/udcp.pdf) were also used. Fat percentage data determined from weekly samples were highly variable and significantly greater than those from DHIA samples. The reason for this variability is unclear, but may be related to inconsistent milk sampling or handling of samples before analysis. Because the average fat percentage data from DHIA sampling was consistent with known performance of the Iowa State University herd, and were alternately collected from morning and evening milkings, only DHIA fat percentage data were used after the first 30 DIM. However, DHIA data were limited during the first 30 DIM due to the monthly sampling schedule. Therefore, data from weekly research samples were used along with DHIA data during this period. Weekly research sample data for the first 30 DIM were adjusted by -0.4794 , which was the difference in average fat percentage between DHIA and weekly research samples during the first 30 DIM. Protein data obtained from weekly samples were consistent with data obtained from monthly DHIA sampling, and all weekly and DHIA protein percent data were included in analyses. Lactose percentage determined from weekly samples were also within the expected range and were included in analyses. Fat and protein percentage records were excluded if less than $1 \%$ or greater than $10 \%$, and lactose percentage data were excluded if less than $2 \%$ or greater than $6 \%$.

Cows were weighed weekly following a morning milking. Body condition was scored weekly by a single trained evaluator, using a 5 -point scale with 0.25 intervals (Elanco Animal Health, 1996). Cows were housed in pens equipped with a Calan Broadbent Feeding system (American Calan Inc., Northwood, NH) and fed ad libitum a TMR formulated to meet or exceed all nutritional requirements (NRC, 2001) throughout the experiment. Each cow was trained to open a single Calan gate to access her assigned feed bin. The TMR was dispensed to each feed bin twice daily, and the quantity of feed dispensed at each feeding was electronically recorded. Orts from each feed bin were removed and weighed daily. Feed intake data were not collected when cows were undergoing treatment that caused their milk to be unsuitable for sale (for example, antibiotic treatment for mastitis). A sample of TMR was collected from at least 4 feedings per week, and from orts on at least $3 \mathrm{~d}$ per week. Equal quantities of these samples were combined to obtain separate weekly samples of TMR and orts. These weekly samples were analyzed by Dairyland Laboratories Inc. (Arcadia, WI) to determine $\mathrm{DM}$ content and $\mathrm{NE}_{\mathrm{L}}$ at 3 times maintenance (Weiss, 1998). Average DM percentage was 50.3 and 48.4 for TMR and orts, respectively, and average $\mathrm{NE}_{\mathrm{L}}$ was 1.63 and $1.58 \mathrm{Mcal} / \mathrm{kg}$ for TMR and orts, 
respectively. Differences between TMR and orts likely reflect sorting of the TMR by cows. These values were used to calculate daily $\mathrm{DM}$ and $\mathrm{NE}_{\mathrm{L}}$ of TMR and orts, followed by calculation of daily $\mathrm{DM}$ and $\mathrm{NE}_{\mathrm{L}}$ intake for each cow. Daily intake records were deleted if exactly 2 records of TMR fed and 1 record of orts were not recorded consecutively, or if DMI intake for the day was less than $2.0 \mathrm{~kg}$.

\section{Energy Balance Traits}

Because data for component traits of EB (milk yield and composition, intake, and $\mathrm{BW}$ ) were recorded on different days, smoothing splines were used to estimate daily phenotypes for traits not measured on a daily basis (fat, protein, and lactose percent, and BW). Smoothing splines were fitted to the data for each trait by cow, using the PROC TRANSREG procedure (SAS Institute, 1999), with a smoothing parameter of 50. For milk component traits, DHIA data for the complete lactation, along with additional data collected during the first 150 DIM, as described previously, were used. This procedure resulted in daily phenotype predictions for each trait, which were combined with traits measured daily (DMI and milk yield) to calculate daily ECM yield and $\mathrm{EB}$ as the difference in $\mathrm{NE}_{\mathrm{L}}$ between energy intake and energy expenditure for production and maintenance. The $\mathrm{NE}_{\mathrm{L}}$ for maintenance was calculated as $0.08 \times$ metabolic $\mathrm{BW}\left(\mathrm{BW}^{0.75}\right)$, and the $\mathrm{NE}_{\mathrm{L}}$ for production was calculated as ECM, as previously described (NRC, 2001). Average EB, DMI, ECM yield, BCS, and BW over monthly intervals (2 to 30 DIM, 31 to 60 DIM, 61 to 90 DIM, 91 to 120 DIM, and 121 to 150 DIM) were calculated as the average of daily (EB, ECM yield, and DMI) or weekly (BW and BCS) values.

\section{Total Production and Gross Feed Efficiency}

Total production over the complete lactation was defined as 305-d ECM yield. Daily predictions of milk components described previously were used along with daily records of milk yield to calculate daily ECM yield for $305 \mathrm{~d}$ of lactation. Smoothing splines were used to predict missing ECM, and daily ECM yield was summed over 305 d to calculate 305-d ECM (ECM305) yield. The ECM305 yield was considered missing for cows with less than 250 actual milk yield records ( $\mathrm{n}=$ 16 cows). Gross feed efficiency was calculated for the first $150 \mathrm{~d}$ of lactation as the sum of daily ECM yield divided by the sum of daily DMI (ECM150/DMI150). The ECM150 yield and DMI150 were calculated as described above, except summed across the first 150 DIM. Eight cows had less than 120 daily milk records for the first 150 DIM and were excluded from GFE analyses. Gross feed efficiency was also calculated for DIM 2 through 74 (GFE2) and for DIM 75 to 150 (GFE75).

\section{Genetic Analyses}

All genetic analyses were done using the ASReml software program (Gilmour et al., 2008). A series of analyses were done to evaluate ECM305 yield, GFE, GFE2, GFE75, EB, DMI, ECM yield, BW, and BCS averaged over monthly intervals. Fixed effects included lactation $(1,2$, or 3 and greater), year-by-season of calving (year, 2008 to 2010; season, January to March, April to June, July to September, or October to December), and age at calving. Age at calving was arbitrarily divided into 14 classes based on age in months and parity, such that each class included at least 19 cows (primiparous: 22, $23,24,25,26,27,28$ to 31 , or 34 to 38 mo; multiparous: 37 to 39,40 to 46,47 to 52,53 to 60,61 to 68 , or 70 to $106 \mathrm{mo})$. The model used for analysis was

$$
y_{i}=\mu+l a c_{i}+Y S C_{i}+A g e_{i}+a_{i}+e_{i},
$$

where $y_{i}=$ individual phenotype; $\mu=$ overall mean; $l a c_{i}=$ fixed effect of lactation (1 to 3 ) for cow $i ; Y S C_{i}$ $=$ fixed effect of year-by-season of calving (1 to 10) for cow $i ; A g e_{i}=$ fixed effect of age at calving class (1 to 14) for cow $i ; a_{i}=$ additive genetic effect of the $i$ th cow, including 5 generations of pedigree relationships for cow $i$; and $e_{i}=$ random residual error. Model 1 was extended to a multivariate model for calculation of genetic and residual correlations among ECM yield, DMI, BW, and BCS by month of lactation. Similarly, bivariate analyses were conducted to estimate genetic and residual correlations between ECM305 yield, GFE, GFE2, or GFE75 and average EB, ECM yield, DMI, $\mathrm{BW}$, and BCS by month of lactation.

Random regression analyses were used to model longitudinal traits over the first half of lactation. Models considered fixed factors described previously, plus the fixed effect of test date of observation. The fixed portion of the lactation curve was modeled using the function described by Ali and Schaeffer (1987), and random regression coefficients for additive genetic and permanent environmental effects were modeled using Legendre polynomials of first and third order, respectively, as follows:

$$
\begin{aligned}
y_{i j} & =l a c_{i}+Y S C_{i}+A g e_{i}+T D_{i j} \\
& +\sum_{n=1}^{4} b_{n} x_{i j k n}(d)+\sum_{n=0}^{1} a_{i} x_{i j k n}(d)+\sum_{n=0}^{3} p_{i} x_{i j k n}(d)+e_{i j},
\end{aligned}
$$


where $y_{i j}=$ phenotype for cow $i$ on test-day $j ; T D_{i j}=$ fixed effect of test day ( $j=1$ to 962 for EB, 1 to 907 for DMI, 1 to 131 for BW and BCS, and 1 to 115 for ECM) for cow $i ; b_{\mathrm{n}}=$ fixed regression coefficient on lactation day $d$, with $x_{i j k 1}(d)=(d / 150), x_{i j k 2}(\mathrm{~d})=(d / 150)^{2}, x_{i j k 3}(d)$ $=\ln (150 / d)$, and $x_{i j k t}(d)=[\ln (150 / d)]^{2} ; a_{i}=$ random regression coefficients for the additive genetic effect of the $i$ th animal, with $x_{i j k 0}(d)=1$ and $x_{i j k 1}(d)=d(i=$ 1 to 1,920$) ; p_{i}=$ random regression coefficients for the permanent environmental effect of cow $i$, with $x_{i j k 0}(d)$ $=1, x_{i j k 1}(d)=d, x_{i j k 2}(d)=1 / 2\left(3 d^{2}-1\right)$, and $x_{i j k 3}(d)=$ $1 / 2\left(5 x^{3}-3 x\right)(i=1$ to 402$)$; and $e_{i j}=$ random error. Phenotypes included daily observations of DMI, weekly observations of $\mathrm{BW}$ and $\mathrm{BCS}$, and daily estimates of ECM yield and EB calculated as described previously. All other terms are as previously defined. Residual errors were expected to have heterogeneous variances and were split into 6 classes ( 2 to 14,15 to 30,31 to 60 , 61 to 90,91 to 120 , and 121 to 150 DIM). Estimates of variance components from this model were used to calculate heritability for each trait and day of lactation.

Model 2 was selected after testing multiple polynomials to confirm that the Ali and Schaeffer (1987) polynomials best described the traits evaluated, as previously reported (Buttchereit et al., 2010). Other polynomials evaluated included those proposed by Wilmink (1987) and Guo and Swalve (1995), and Legendre polynomials up to the fourth order. Preliminary analyses also evaluated random effect terms of the models with regard to order of the Legendre polynomial, up to third order. In general, higher-order polynomials for the permanent environmental effect were superior, whereas higher orders for the genetic effect offered no advantage or failed to converge. The final model was selected based on the Akaike information criterion and convergence (data not shown).

\section{RESULTS AND DISCUSSION}

A summary of raw data and daily or weekly means of analyzed traits are provided in Table 1 and Figure 1, respectively. The average daily ECM yield of cows in the current study was greater than that described in several recent reports. Primiparous and multiparous cows in the current study required 26.2 and 34.3 Mcal of $\mathrm{NE}_{\mathrm{L}}$, respectively, compared with 20 to 24 Mcal of $\mathrm{NE}_{\mathrm{L}}$ for primiparous cows (Hüttmann et al., 2009; Buttchereit et al., 2011), or $24 \mathrm{Mcal}$ of $\mathrm{NE}_{\mathrm{L}}$ for mixedparity cows (Vallimont et al., 2010), when ECM yield was calculated according to NRC (2001). However, the current study included only the first 150 DIM, whereas others included DIM 11 to 180 (Hüttmann et al., 2009; Buttchereit et al., 2011) or the complete lactation (Vallimont et al., 2010). The DMI and BW of primiparous cows in the current study $(20.4$ and $554 \mathrm{~kg}$, respectively) were similar to those described by others (Hüttmann et al., 2009; Buttchereit et al., 2011). Likewise, EB profiles of cows in the current study were similar to those previously reported, except that primiparous cows remained in negative EB for a longer period of time (65 vs. approximately 45 d; Hüttmann et al., 2009; Buttchereit et al., 2011). This difference is consistent with greater production, but similar DMI and BW for cows in the current, compared with previous studies. Multiparous cows in the studied population returned to positive EB at approximately 75 DIM, similar to 83 DIM previously described for primiparous plus multiparous cows (Banos and Coffey, 2010).

\section{Heritability Estimates}

Estimates of heritability determined from trait averages over monthly intervals (Table 2) confirm a

Table 1. Summary of data recorded for all traits ${ }^{1}$

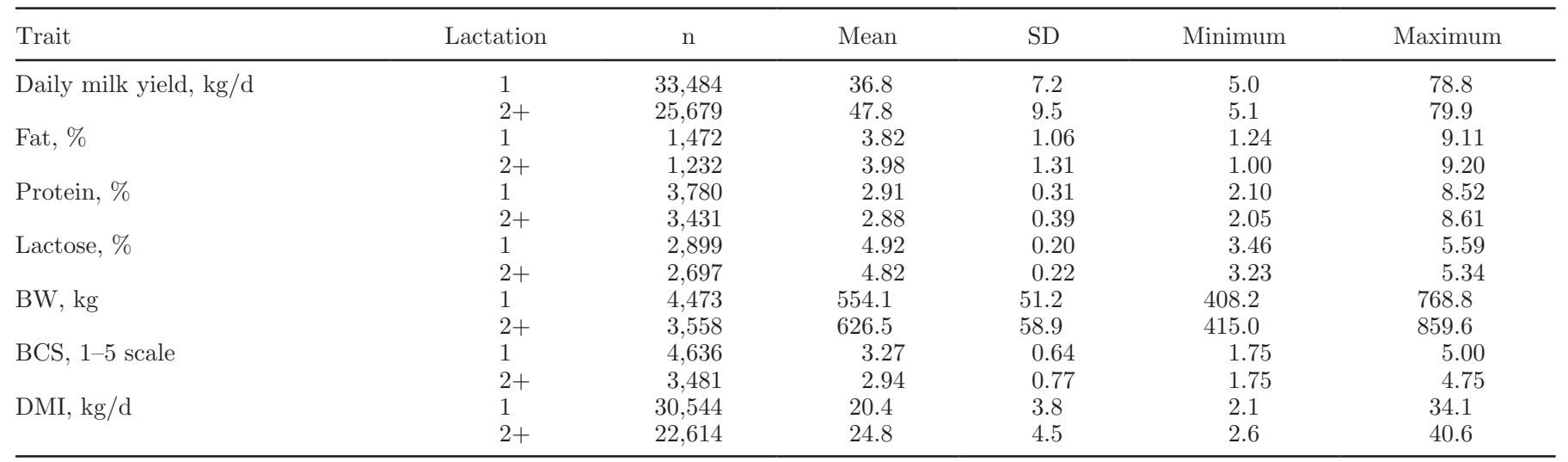

${ }^{1}$ Data were collected from a single lactation from primiparous (lactation $=1 ; \mathrm{n}=227$ ) and multiparous (lactation $=2+; \mathrm{n}=175$ ) Holstein cows, from 2 through 150 DIM. 
A

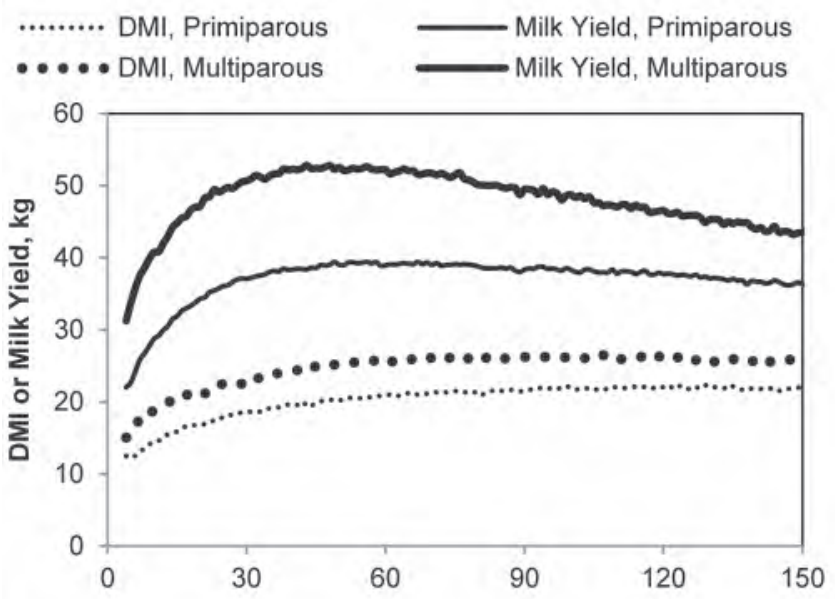

B

_Energy Balance, Primiparous __ Energy Balance, Multiparous

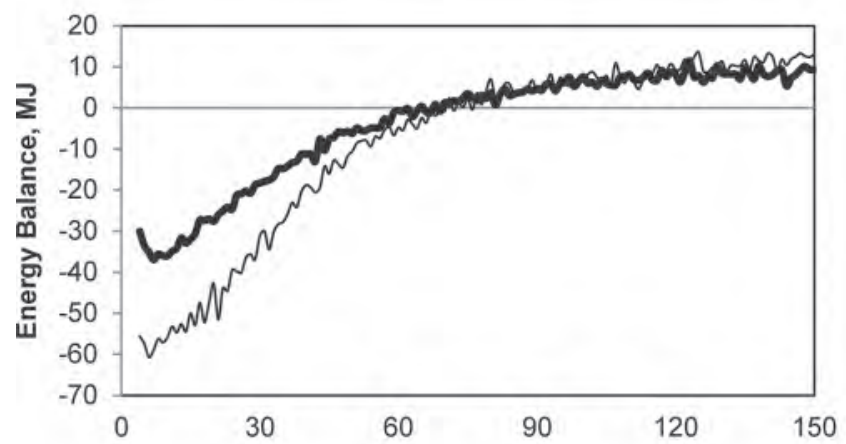

C

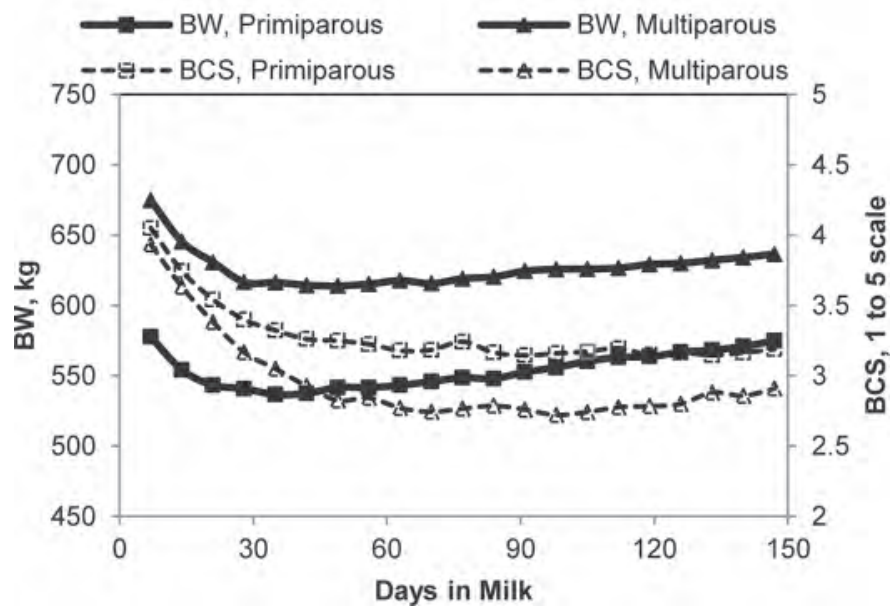

Figure 1. Average daily DMI and milk yield (A), energy balance (B), and average weekly BW and BCS (C) in primiparous and multiparous cows. moderate to high heritability of BW and BCS (0.48 to 0.74 ), and moderate heritability for ECM yield, DMI, and EB (0.10 to 0.63). Daily estimates of heritability generated from random regression models ranged from 0.18 to $0.30,0.10$ to $0.26,0.43$ to $0.67,0.25$ to 0.38 , and 0.07 to 0.22 for DMI, ECM yield, BW, BCS, and $\mathrm{EB}$, respectively, when data from all cows were considered (Figures 2 and 3). Results from monthly averages and random regression models had similar trends over DIM. Estimates from the analyses of monthly averages were consistently greater than those from the random regression model, as expected for the analysis of average rather than individual observations (Falconer and Mackay, 1996).

The high heritability estimates for BW and BCS in the current study represent the upper range of estimates from the current literature, with previous BW heritability estimates ranging from 0.29 to 0.60 (Karacaören et al., 2006; Hüttmann et al., 2009; Vallimont et al., 2010) and BCS heritability estimates ranging from 0.24 to 0.56 (Banos and Coffey, 2010; Vallimont et al., 2010; Buttchereit et al., 2011). In the current study, care was taken to measure BW as cows exited the parlor before their morning feeding to minimize potential variation due to gut and udder fill. Body condition score is a subjective trait scored by visual appraisal, and its residual variation is due in part to the skill and consistency of the evaluator. In the current study, a single trained technician scored all cows throughout the study. It should also be noted that BCS heritability estimates were greater for data averaged over monthly intervals (0.49 to 0.53 ) compared with daily estimates from random regression analyses (0.25 to 0.38 ), as expected for the heritability of means (Falconer and Mackay, 1996). These factors may have contributed to the relatively high heritability estimates of BW and BCS obtained in the current study.

Moderate heritability estimates were observed for ECM yield, as well as for DMI and EB. Estimates of DMI heritability from this study (0.18 to 0.60$)$ are similar to or greater than those previously described (0.04 to 0.54; Veerkamp and Thompson, 1999; Karacaören et al., 2006; Hüttmann et al., 2009; Vallimont et al., 2010; Buttchereit et al., 2011). Heritability estimates for EB are within a similar range for the present and previous studies (0.04 to 0.34; Coffey et al., 2004; Hüttmann et al., 2009; Buttchereit et al., 2011), but have minor differences in trajectory. In the current experiment, heritability of EB peaked at approximately 30 DIM, whereas maximal estimates were previously observed at the onset of lactation (Coffey et al., 2004; Hüttmann et al., 2009; Buttchereit et al., 2011). Although the reason for this difference is unclear, differences in milk composition data collection during the first 30 DIM may 
Table 2. Estimates of heritability (SE) and genetic correlations (SE) for ECM yield, DMI, BW, and BCS by month of lactation ${ }^{1}$

\begin{tabular}{|c|c|c|c|c|}
\hline Item & ECM & DMI & BW & $\mathrm{BCS}$ \\
\hline \multicolumn{5}{|l|}{ Month 1} \\
\hline ECM yield & $0.10(0.10)$ & $0.61(0.33)$ & $0.33(0.33)$ & $-0.08(0.39)$ \\
\hline DMI & & $0.34(0.11)$ & $0.74(0.14)$ & $0.32(0.22)$ \\
\hline BW & & & $0.71(0.12)$ & $0.61(0.12)$ \\
\hline BCS & & & & $0.52(0.13)$ \\
\hline \multicolumn{5}{|l|}{ Month 2} \\
\hline ECM yield & $0.36(0.13)$ & $0.72(0.12)$ & $0.31(0.20)$ & $-0.17(0.24)$ \\
\hline DMI & & $0.60(0.14)$ & $0.50(0.14)$ & $-0.13(0.21)$ \\
\hline BW & & & $0.67(0.13)$ & $0.52(0.14)$ \\
\hline BCS & & & & $0.52(0.13)$ \\
\hline \multicolumn{5}{|l|}{ Month 3} \\
\hline ECM yield & $0.61(0.12)$ & $0.73(0.09)$ & $0.22(0.18)$ & $-0.23(0.19)$ \\
\hline DMI & & $0.54(0.14)$ & $0.48(0.16)$ & $-0.06(0.22)$ \\
\hline BW & & & $0.57(0.13)$ & $0.58(0.14)$ \\
\hline BCS & & & & $0.48(0.13)$ \\
\hline \multicolumn{5}{|l|}{ Month 4} \\
\hline ECM yield & $0.26(0.12)$ & $0.73(0.16)$ & $0.38(0.22)$ & $-0.31(0.25)$ \\
\hline DMI & & $0.29(0.12)$ & $0.80(0.16)$ & $0.14(0.26)$ \\
\hline BW & & & $0.74(0.12)$ & $0.59(0.12)$ \\
\hline BCS & & & & $0.55(0.13)$ \\
\hline \multicolumn{5}{|l|}{ Month 5} \\
\hline ECM yield & $0.17(0.11)$ & $0.62(0.24)$ & $0.40(0.29)$ & $-0.35(0.30)$ \\
\hline DMI & & $0.22(0.11)$ & $0.91(0.18)$ & $0.15(0.29)$ \\
\hline BW & & & $0.69(0.12)$ & $0.48(0.14)$ \\
\hline BCS & & & & $0.48(0.13)$ \\
\hline
\end{tabular}

${ }^{1}$ All data from primiparous and multiparous cows were included in analyses $(\mathrm{n}=402)$. Within each month, heritability estimates are shown on the diagonal and genetic correlations are shown above the diagonal.

have contributed, as samples were primarily collected from a single morning milking in this study. However, results across studies consistently describe DMI and EB as lowly to moderately heritable traits that would likely respond to selection pressure.

Heritability estimates were similar between primiparous and multiparous cows for BW and ECM yield. However, subtle differences were noted for BCS, EB, and DMI. In primiparous cows, BCS heritability estimates were greatest at the onset of lactation, and then decreased to moderate levels over the next 4 mo. In contrast, BCS heritability estimates in multiparous cows were lowest at the onset of lactation, and then increased to higher levels as lactation progressed. Heritability estimates for DMI were greatest for multiparous cows during the first 3 mo of lactation, and then decreased dramatically to nonsignificant values after 90 DIM. Heritability estimates for DMI in primiparous cows were relatively consistent across the first 5 mo of lactation. Energy balance heritability estimates for both primiparous and multiparous cows increased, and then decreased over the first 5 mo of lactation. However, the peak heritability occurred earlier in multiparous (mo 3) compared with primiparous (mo 4) cows. Differences in heritability estimates between primiparous and multiparous cows may reflect differences in metabolism, such as a need for primiparous cows to partition energy resources toward growth (Wathes et al., 2007). However, the number of cows included in the separate multiparous and primiparous data sets in this study was relatively small (227 and 175 , respectively), and the multiparous data set may represent a biased population, because only cows that successfully completed 2 or more lactations were included. Therefore, differences in heritability estimates between primiparous and multiparous cows should be interpreted with caution and warrant further investigation. For example, the estimate of EB heritability for multiparous cows in the third month of lactation was 1 , which is clearly inflated.

\section{Genetic Correlations}

For each trait, genetic correlations between the trait at different DIM were determined using random regression models. Consistent with previous research (Veerkamp and Thompson, 1999; Karacaören et al., 2006; Hüttmann et al., 2009), correlations between DIM were high (>0.7) for BCS, BW, and ECM yield (results not shown). However, the genetic correlations between DMI in early and mid lactation also remained greater than 0.7 in the current study (Figure 4). This high genetic correlation across DIM was also observed with bivariate analyses of average monthly DMI (data 
A

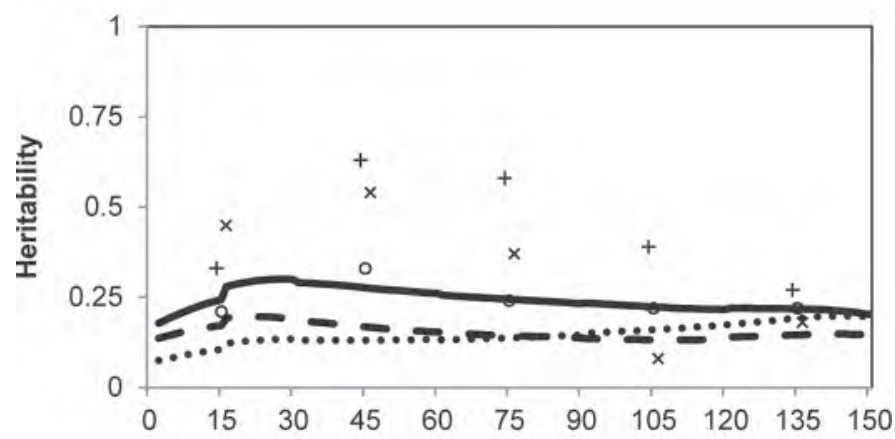

B

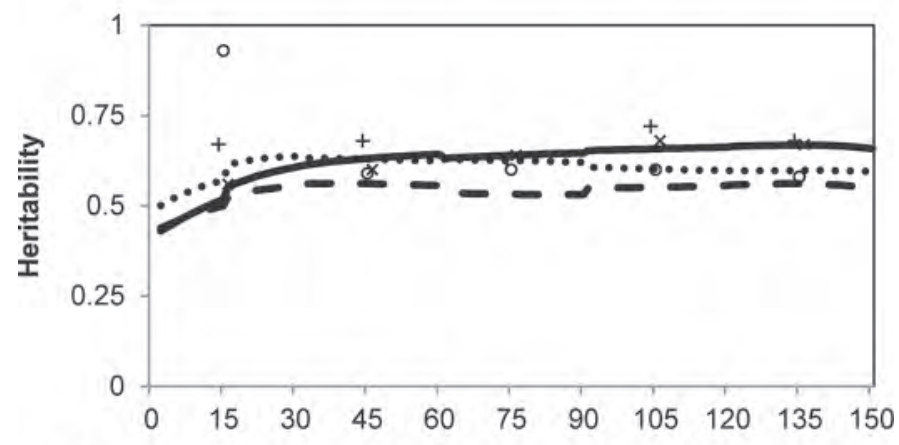

C

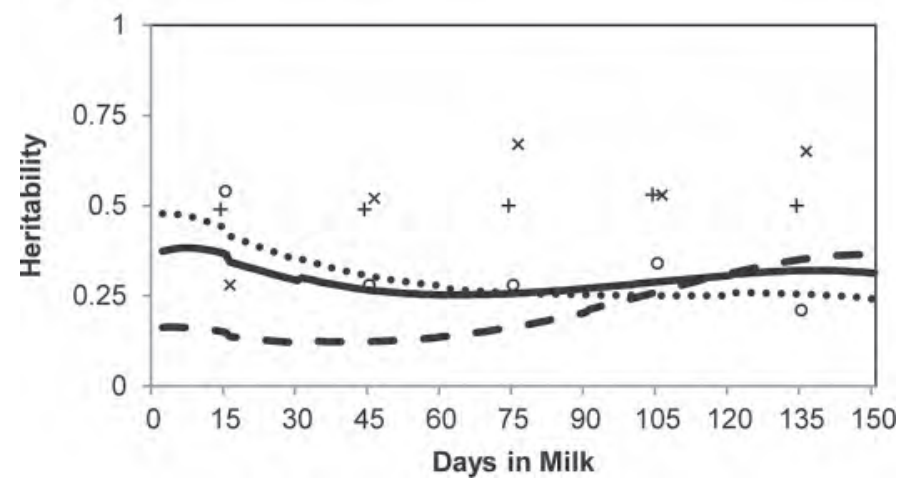

Figure 2. Heritability estimates for DMI (A), BW (B), and BCS (C). Lines represent estimates of daily heritability obtained from random regression analyses including all (solid, $\mathrm{n}=402$ ), primiparous (dotted, $\mathrm{n}=227$ ), or multiparous (dashed, $\mathrm{n}=175$ ) cows. Symbols represent heritability estimates from univariate analyses of each trait averaged over monthly intervals. Analyses included all (+), primiparous $(O)$, or multiparous $(\times)$ cows. Standard errors of heritability estimates from univariate analyses ranged from 0.09 to $0.14,0.14$ to 0.26 , and 0.18 to 0.27 for all, primiparous, and multiparous cows, respectively.

not shown). This result differs from other studies that describe a rapidly decreasing (Veerkamp and Thompson, 1999; Karacaören et al., 2006; Hüttmann et al., 2009), or negative (Buttchereit et al., 2011) genetic correlation between DMI in early lactation and DMI in mid or late lactation. It should be noted that cows
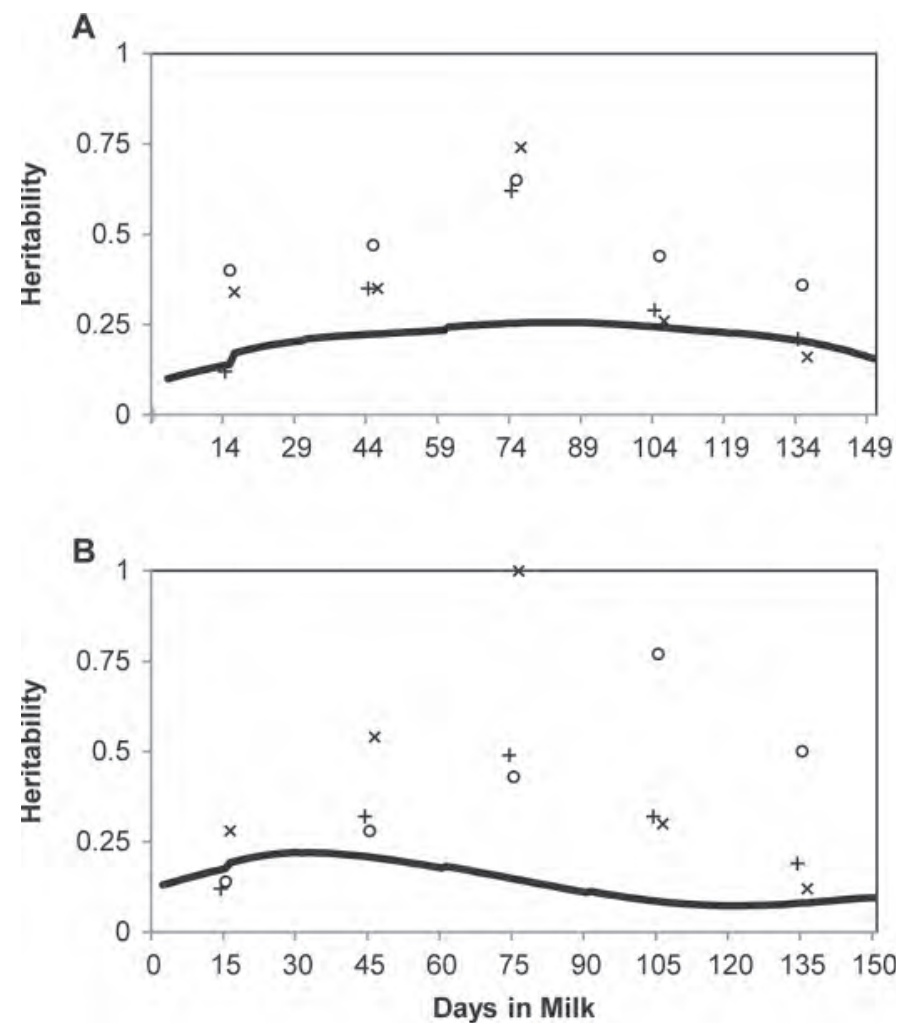

Figure 3. Heritability estimates for ECM yield (A) and energy balance (B). Lines represent estimates of daily heritability obtained from random regression analyses including all $(\mathrm{n}=402)$ cows. Random regression analyses using only primiparous $(\mathrm{n}=227)$ or multiparous $(\mathrm{n}=175)$ cows failed to converge for these traits. Symbols represent heritability estimates from univariate analyses of each trait averaged over monthly intervals. Analyses included all $(+)$, primiparous $(\bigcirc)$, or multiparous $(x)$ cows. Standard errors of heritability estimates from univariate analyses ranged from 0.09 to $0.14,0.14$ to 0.26 , and 0.18 to 0.27 for all, primiparous, and multiparous cows, respectively.

in the present study had been trained and acclimated to the Calan gate feeding system during the dry period before the studied lactation. Although they moved to a different location and Calan gate after parturition, they may have acclimated to this change differently than cows without previous exposure to the feeding system. This potential management difference may have contributed to differences between this and other experiments, particularly at the onset of lactation. In contrast to the component traits from which EB is derived, the correlation between EB in early lactation and EB in mid lactation decreased until a negative genetic correlation between EB at 10 DIM and EB at 135 to 150 DIM was observed (Figure 4). This trend is consistent with results described by others (Hüttmann et al., 2009; Buttchereit et al., 2011). Together, these studies support the conclusion that the genetic regulation of EB differs between stages of lactation, and highlights 


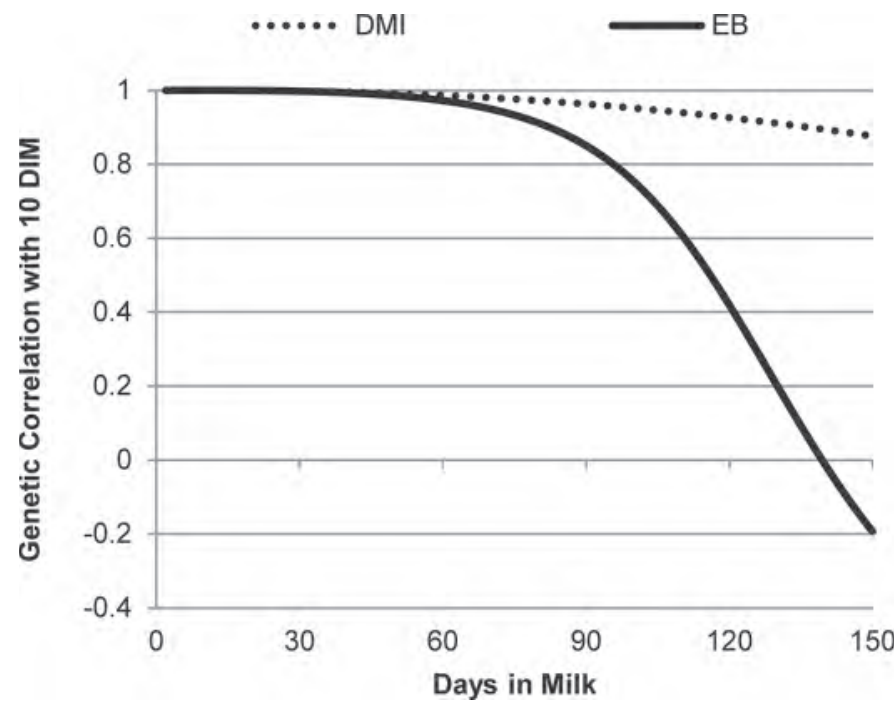

Figure 4. Genetic correlations between different DIM were determined by random regression analyses for DMI and energy balance (EB). For each trait, the genetic correlation between 10 DIM and 2 through 150 DIM is shown.

the need to carefully consider stage of lactation when estimating genetic correlations among traits relating to feed intake and production.

Genetic correlations among traits were estimated using multivariate and bivariate analyses where each trait averaged for each month of lactation was considered a separate trait. Consistent and positive correlations were observed for DMI with ECM yield and BW, and for BW with BCS (Table 2). The genetic correlation between BCS and ECM yield was consistently negative and became stronger with increasing DIM. However, this correlation did not reach statistical significance due to large standard errors. This relationship is consistent with greater ECM production in cows that are better able to mobilize body energy reserves in early lactation, and cows that continue to partition energy toward production, rather than replenishing fat stores, in mid lactation. Similarly, the genetic correlation between DMI and BCS changes over lactation, although standard errors remained large. Initially, this correlation was positive, followed by negative correlations in mo 2 and 3 , and finally returning to positive correlations in mo 4 and 5 . The negative correlations between DMI and BCS in mo 2 and 3 likely reflect increased intake as well as increased mobilization of energy reserves in high-producing cows during peak lactation.

As selection strategies to improve production efficiency are considered, an understanding of genetic correlations between DMI, BW, BCS, and EB at different stages of lactation, and production and efficiency over the complete lactation is needed. In the current study, heritability estimates for ECM305 yield (means \pm SE) were $0.29 \pm 0.13,0.49 \pm 0.25$, and $0.26 \pm 0.22$ for all, primiparous, and multiparous cows, respectively. These estimates are consistent with current heritability estimates (0.30) for production traits from Holstein genetic evaluation programs in the United States (USDAAIPL, 2012). A positive genetic correlation between ECM305 yield and DMI was observed throughout the first 5 mo of lactation $(P<0.05)$, whereas ECM305 yield was negatively correlated with EB for mo 2 and 3 $(P<0.05$; Table 3$)$. The correlation of ECM305 yield with BCS was -0.32 to -0.36 for mo 2 through 5 , but had large standard errors. These genetic correlations are similar to estimates previously described, when production over a complete lactation was studied. For example, 305-d FCM yield was negatively correlated with BCS $(-0.33)$, and positively correlated with DMI (0.52) based on field data (Vallimont et al., 2010). Similarly, selection for increased fat plus protein resulted in cows that maintained significantly less body energy compared with randomly selected cows (Coffey et al., 2004). Also, lactation milk yield was significantly correlated with EB summed over the complete negative EB period (0.33), the nadir of energy content $(-0.48)$, and the number of DIM until the nadir of energy content was reached (0.63; Banos and Coffey, 2010). Together these results indicate that increased overall production is associated with greater feed intake and the maintenance of a lower energy status. However, the genetic correlation between ECM305 yield and EB during the first month of lactation was -0.02 in the current study. This result is important because it suggests that a more severe negative EB during the initial transition from pregnancy to lactation is not associated with increased production over the course of lactation, and that selection for increased production without a further decline in EB during the first month of lactation may be feasible. Additionally, the correlation between ECM305 yield and BW was less than 0.30 and not statistically significant $(P>0.05)$, indicating that larger cows do not offer a significant advantage of increased production in this population. However, this analysis included primiparous cows that continued to grow during the studied lactation. Thus, their BW may not accurately reflect their mature body size.

\section{Gross Feed Efficiency}

Heritability estimates (means $\pm \mathrm{SE}$ ) for GFE were $0.32 \pm 0.13,0.47 \pm 0.23$, and $0.43 \pm 0.25$ for all, primiparous, and multiparous cows, respectively. These estimates are similar to heritability estimates for production traits, and consistent with previous estimates 
Table 3. Genetic correlations (SE) between ECM yield across the complete lactation (305-d ECM, ECM305), gross feed efficiency (GFE) from 2 through 150 DIM, GFE from 2 through 74 DIM (GFE2), and GFE from 75 through 150 DIM (GFE75), and BW, DMI, BCS, and energy balance (EB), by month of lactation

\begin{tabular}{|c|c|c|c|c|c|}
\hline Item & \multicolumn{5}{|c|}{ Month of lactation } \\
\hline \multicolumn{6}{|c|}{ Correlations with ECM305 yield } \\
\hline DMI & $0.75(0.23)$ & $0.75(0.14)$ & $0.83(0.11)$ & $0.87(0.14)$ & $0.78(0.18)$ \\
\hline BCS & $-0.06(0.28)$ & $-0.36(0.26)$ & $-0.38(0.25)$ & $-0.32(0.25)$ & $-0.36(0.24)$ \\
\hline $\mathrm{EB}$ & $-0.02(0.45)$ & $-0.53(0.24)$ & $-0.43(0.22)$ & $-0.11(0.30)$ & $-0.48(0.34)$ \\
\hline ECM yield & $0.42(0.34)$ & $0.68(0.17)$ & $0.72(0.13)$ & $0.57(0.21)$ & $0.56(0.27)$ \\
\hline DMI & $-0.22(0.28)$ & $-0.20(0.23)$ & $-0.07(0.25)$ & $-0.05(0.29)$ & $-0.06(0.34)$ \\
\hline $\mathrm{BCS}$ & $-0.18(0.26)$ & $-0.20(0.26)$ & $-0.40(0.23)$ & $-0.48(0.21)$ & $-0.48(0.21)$ \\
\hline $\mathrm{EB}$ & $-0.73(0.27)$ & $-0.94(0.09)$ & $-0.99(0.07)$ & 1 & $-0.87(0.21)$ \\
\hline \multicolumn{6}{|l|}{ Correlations with GFE2 } \\
\hline $\mathrm{EB}$ & $-0.97(0.20)$ & $-0.95(0.08)$ & $-0.99(0.10)$ & $-^{1}$ & $-0.81(0.31)$ \\
\hline \multicolumn{6}{|l|}{ Correlations with GFE75 } \\
\hline
\end{tabular}

${ }^{1}$ Model converged with boundary estimates.

of GFE (see Veerkamp and Emmans, 1995), but greater than a more recent estimate (0.16; Vallimont et al., 2011). The latter estimate was based on DMI measured on commercial farms, and included data from complete lactations, whereas the current study was done on a research farm where DMI was only measured for the first half of lactation. As expected, improved efficiency was associated with increased ECM during each of the first 5 mo of lactation $(P<0.05$; Table 3$)$. However, the genetic correlation between GFE and DMI was not different from zero. Thus, improved efficiency in this population is closely associated with ECM yield, but not DMI. Consistent with this relationship, a strong negative genetic correlation was observed between GFE and EB, such that improved efficiency is associated with lower EB status throughout the first half of lactation. This result is consistent with a strong correlation between GFE and BCS change previously described, based on field data collected across multiple herds (Vallimont et al., 2011). To further investigate this relationship between GFE and EB, GFE was calculated for DIM 2 through 74 (GFE2), and for DIM 75 through 150 (GFE75) when the majority of cows were in negative or positive EB, respectively. Heritability estimates for GFE2 and GFE75 were $0.32 \pm 0.13$ and $0.20 \pm$ 0.12 , respectively, and the genetic correlation between these traits was $0.96 \pm 0.18$. The genetic correlations of GFE2 and GFE75 with average EB in the first month of lactation were $-0.97 \pm 0.20$ and $-0.38 \pm 0.47$, respectively, compared with $-0.73 \pm 0.27$ for the correlation between total GFE and EB in the first month of lactation (Table 3). Together, these genetic parameters indicate the genetic regulation of GFE is similar be- tween the first and second 75 DIM, such that selection based on GFE measured after the return to positive EB should be effective at improving overall efficiency. Additionally, the genetic correlation between GFE and EB during the first month of lactation is greatly reduced when efficiency is calculated without data from the first 75 DIM. Thus, it may be feasible to improve overall gross efficiency without a severe antagonistic effect on EB during the first month of lactation, when negative EB is of greatest concern. However, further research is needed to optimize selection for improved efficiency, including investigation of the optimal stage of lactation for measurement of feed intake and efficiency traits, and alternate definitions of efficiency such as residual feed efficiency (see Connor et al., 2012).

\section{CONCLUSIONS}

In summary, DMI and EB are traits that will likely respond to selection pressure. The genetic regulation of EB differs between early and mid lactation, and an unfavorable genetic correlation between EB in early lactation and GFE exists. However, this correlation diminishes when GFE is calculated for the second 75 DIM, or after cows return to positive EB. Thus, improvement in efficiency, without an unfavorable correlated change in EB during early lactation, may be achievable.

\section{ACKNOWLEDGMENTS}

This project was supported by National Research Initiative Competitive Grant no. 2008-35205-18711 from the US Department of Agriculture National In- 
stitute of Food and Agriculture (Washington, DC), and by funding from Merial/Igenity (Lincoln, NE).

\section{REFERENCES}

Ali, T. E., and L. R. Schaeffer. 1987. Accounting for covariances among test day milk yields in dairy cows. Can. J. Anim. Sci. 67:637-644.

Banos, G., and M. P. Coffey. 2010. Genetic association between body energy measured throughout lactation and fertility in dairy cattle. Animal 4:189-199.

Brody, S. 1945. Bioenergetics and Growth. Reinhold Publishing Corp., New York, NY.

Buttchereit, N., E. Stamer, W. Junge, and G. Thaller. 2010. Evaluation of five lactation curve models fitted for fat:protein ratio of milk and daily energy balance. J. Dairy Sci. 93:1702-1712. http://dx.doi.org/10.3168/jds.2009-2198.

Buttchereit, N., E. Stamer, W. Junge, and G. Thaller. 2011. Short communication: Genetic relationships among daily energy balance, feed intake, body condition score, and fat to protein ratio of milk in dairy cows. J. Dairy Sci. 94:1586-1591. http://dx.doi. org/10.3168/jds.2010-3396.

Coffey, M. P., G. Simm, J. D. Oldham, W. G. Hill, and S. Brotherstone. 2004. Genotype and diet effects on energy balance in the first three lactations of dairy cows. J. Dairy Sci. 87:4318-4326. http://dx.doi.org/10.3168/jds.S0022-0302(04)73577-8.

Connor, E. E., J. L. Hutchison, K. M. Olson, and H. D. Norman. 2012 Opportunities for improving milk production efficiency in dairy cattle. J. Anim. Sci. 90:1687-1694. http://dx.doi.org/10.2527/ jas.2011-4528.

Elanco Animal Health. 1996. Body Condition Scoring in Dairy Cattle. Vol. A1 8478. Elanco Animal Health, Greenfield, IN.

Falconer, D. S., and T. S. Mackay. 1996. Pages 139-142 in Introduction to Quantitative Genetics. 4th ed. Longman Group Ltd., Essex, UK.

Gilmour, A. R., B. J. Gogel, B. R. Cullis, and R. Thompson. 2008 ASReml User Guide. Release 3.0. VSN International Ltd., Hemel Hempstead, UK.

Guo, Z., and H. H. Swalve. 1995. Modelling of the lactation curve as a sub-model in the evaluation of test day records. Interbull Bull. $11: 22-25$.

Hüttmann, H., E. Stamer, W. Junge, G. Thaller, and E. Kalm. 2009. Analysis of feed intake and energy balance of high-yielding first lactating Holstein cows with fixed and random regression models. Animal 3:181-188.

Karacaören, B., F. Jaffrézic, and H. N. Kadarmideen. 2006. Genetic parameters for functional traits in dairy cattle from daily random regression models. J. Dairy Sci. 89:791-798. http://dx.doi. org/10.3168/jds.S0022-0302(06)72141-5.

NRC. 2001. Nutrient Requirements of Dairy Cattle. 7th ed. Natl Acad. Press, Washington, DC.

Oltenacu, P. A., and D. M. Broom. 2010. The impact of genetic selection for increased milk yield on the welfare of dairy cows. Anim. Welf. 19(Suppl. 1):39-49.

Pryce, J. E., M. P. Coffey, and G. Simm. 2001. The relationship between body condition score and reproductive performance. J. Dairy Sci. 84:1508-1515. http://dx.doi.org/10.3168/jds.S00220302(01)70184-1.
SAS Institute. 1999. SAS/STAT User's Guide. SAS Institute Inc. Cary, NC.

Simm, G., C. Smith, and R. Thompson. 1987. The use of product traits such as lean growth rate as selection criteria in animal breeding. Anim. Prod. 45:307-316.

USDA-AIPL (US Department of Agriculture-Animal Improvement Programs Laboratory). 2012. Trait parameters. Accessed Mar. 26 2012. http://aipl.arsusda.gov/reference/nmcalc.htm.

USDA-NASS (US Department of Agriculture-National Agricultura Statistics Service). 2012. Agricultural Resource Management Survey. Accessed Mar. 26, 2012. http://quickstats.nass.usda.gov/results/C85CB595-2E39-3AAF-A13F-420248669E58?pivot=short_ desc.

Vallimont, J. E., C. D. Dechow, J. M. Daubert, M. W. Dekleva, J. W. Blum, C. M. Barlieb, W. Liu, G. A. Varga, A. J. Heinrichs, and C. R. Baumrucker. 2010. Genetic parameters of feed intake, production, body weight, body condition score, and selected type traits of Holstein cows in commercial tie-stall barns. J. Dairy Sci. 93:4892-4901. http://dx.doi.org/10.3168/jds.2010-3189.

Vallimont, J. E. C. D. Dechow, J. M. Daubert, M. W. Dekleva, J. W. Blum, C. M. Barlieb, W. Liu, G. A. Varga, A. J. Heinrichs, and C. R. Baumrucker. 2011. Short communication: Heritability of gross feed efficiency and associations with yield, intake, residual intake, body weight, and body condition score in 11 commercial Pennsylvania tie stalls. J. Dairy Sci. 94:2108-2113. http://dx.doi. org/10.3168/jds.2010-3888.

van Arendonk, J. A. M., G. J. Nieuwhof, H. Vos, and S. Korver. 1991 Genetic aspects of feed intake and efficiency in lactating dairy heifers. Livest. Prod. Sci. 29:263-275.

Veerkamp, R. F., and G. C. Emmans. 1995. Review: Sources of genetic variation in energetic efficiency of dairy cows. Livest. Prod. Sci 44:87-97.

Veerkamp, R. F., E. P. C. Koenen, and G. De Jong. 2001. Genetic correlations among body condition score, yield, and fertility in first-parity cows estimated by random regression models. J. Dairy Sci. 84:2327-2335. http://dx.doi.org/10.3168/jds.S00220302(01)74681-4.

Veerkamp, R. F., and R. Thompson. 1999. A covariance function for feed intake, live weight, and milk yield estimated using a random regression model. J. Dairy Sci. 82:1565-1573. http://dx.doi. org/10.3168/jds.S0022-0302(99)75384-1.

Verbyla, K. L., M. P. L. Calus, H. A. Mulder, Y. de Haas, and R. F. Veerkamp. 2010. Predicting energy balance for dairy cows using high-density single nucleotide polymorphism information. J. Dairy Sci. 93:2757-2764. http://dx.doi.org/10.3168/jds.2009-2928.

Wathes, D. C., Z. Cheng, N. Bourne, V. J. Taylor, M. P. Coffey, and S. Brotherstone. 2007. Differences between primiparous and multiparous dairy cows in the inter-relationships between metabolic traits, milk yield and body condition score in the periparturient period. Domest. Anim. Endocrinol. 33:203-225. http://dx.doi. org/10.1016/j.domaniend.2006.05.004.

Weiss, W. P. 1998. Estimating the available energy content of feeds for dairy cattle. J. Dairy Sci. 81:830-839. http://dx.doi.org/10.3168/ jds.S0022-0302(98)75641-3.

Wilmink, J. B. M. 1987. Adjustment of test-day milk, fat and protein yield for age, season and stage of lactation. Livest. Prod. Sci $16: 335-348$. 